\title{
Repolarização Precoce no Eletrocardiograma do Atleta. Bases Iônicas e Modelo Vetorial
}

\author{
Eduardo Corrêa Barbosa, Paulo Roberto Benchimol Barbosa, Alfredo de Souza Bomfim, \\ Plínio José da Rocha, Paulo Ginefra
}

Rio de Janeiro, $\mathbf{R J}$

\begin{abstract}
O padrão eletrocardiográfico do atleta mimetiza várias alterações encontradas em diversas cardiopatias, fazendo com que, em um passado recente, tenham sido cometidas condutas equivocadas, como a pressuposição da presença de cardiopatia e afastamento de esportistas de suas atividades. Esta revisão procura rever os mecanismos pelos quais o exercício modifica a modulação autonômica sobre o coraçãoe propõe explicações, baseadas em mecanismos eletrofisiológicos e na teoria vetorial da ativação cardíaca, para o padrão eletrocardiográfico conhecido como repolarização precoce.
\end{abstract}

\section{A Remodelagem da modulação autonômica do coração de atletas}

O treinamento físico, em especial o continuado e de alto desempenho, produz várias e significativas modificações nos sistemas cardiovascular e nervoso autonômico. $\mathrm{O}$ condicionamento físico é tradicionalmente avaliado pela determinação da resposta cronotrópica ao exercício ${ }^{1}$. A redução da frequiência cardíaca em repouso e da magnitude de sua variação durante o exercício tem sido interpretada como um efeito combinado sobre os sistemas simpático e parassimpático ${ }^{2,3}$. Estudos que analisaram a variabilidade da freqüência cardíaca no domínio da freqüência demonstraram que tanto os componentes de baixa freqüência que refletem as contribuições simpática e parassimpática como os de alta frequiência, que refletem predominantemente a atividade vagal, são influenciados pelo treinamento físico ${ }^{4-7}$. Os registros da variabilidade da freqüência cardíaca sob ventilação controlada demonstraram uma maior potência espectral dos componentes de alta freqüência em repouso nos indivíduos treinados em relação aos não treinados, traduzindo um aumento da atividade vagal em repouso nos atletas ${ }^{6}$.

A remodelagem da modulação autonômica do coração

Universidade do Estado do Rio de Janeiro

Correspondência: Eduardo Corrêa Barbosa - Rua Alzira Cortez, 5/101

Cep 22260-050 - Rio de Janeiro, RJ

Recebido para publicação em 18/11/02

Aceito em 31/3/03 secundária ao treinamento e que inclui a redução da atividade simpática e aumento da parassimpática tem como possíveis mecanismos: 1) dessensibilização dos receptores Badrenérgicos cardíacos ou uma redução de sua densidade conseqüente à estimulação freqüente e sustentada, como a que ocorre no treinamento físico. A redução da densidade destes receptores pode ser generalizada ${ }^{8,9}$ ou localizada, preferencialmente, na parede inferior do ventrículo esquer$\mathrm{do}^{10}$, conforme atestam estudos que avaliam a integridade do sistema simpático através da cintilografia de captação com 123-metaiodobenzilguanidina; 2) o aumento do inotropismo no coração treinado gera uma maior estimulação dos barorreflexos incluindo os receptores do bulbo carotídeo e os pressorreceptores ventriculares esquerdos com conseqüente estimulação aferente vagal e incremento do tônus parassimpático ${ }^{11,12} ; 3$ ) o aumento do tônus vagal contribui para diminuição do tônus simpático através do fenômeno denominado antagonismo acentuado ${ }^{13}$. A maior liberação de acetilcolina antagoniza os efeitos adrenérgicos através de dois mecanismos: pré-juncional e pós-juncional. O primeiro é secundário à liberação conjunta de acetilcolina e neuropeptídeo Y tendo este a função de inibir a liberação de norepinefrina nos terminais sinápticos e o segundo é devido a uma ação competitiva entre a acetilcolina e norepinefrina sobre a enzima adenilciclase, a primeira inibindo e a segunda ativando a ação desta enzima; 4) alterações eletrofisiológicas intrínsecas da célula cardíaca ocasionadas pelo estiramento e hipertrofia miocárdica que acompanham o treinamento físico continuado. Estas alterações seriam responsáveis pela bradicardia sinusal e alentecimento da condução atrioventricular em atletas, mesmo na presença de bloqueio farmacológico do sistema autonômico ${ }^{14}$.

Estes mecanismos, provavelmente em conjunto, são responsáveis pelo balanço autonômico característico dos atletas.

\section{As Bases iônicas da ativação elétrica do coração}

O coração só exerce sua função de bomba se, previamente, sofrer uma despolarização elétrica. O registro da atividade elétrica transmembrana, ao longo do ciclo cardíaco, é de- 
nominado de potencial de ação da célula cardíaca. As modificações da voltagem elétrica intracelular são decorrentes da ativação e inativação de correntes iônicas, através de proteínas inseridas perpendicularmente na membrana celular e que formam os canais iônicos. A condutância iônica nestes canais é modulada por vários mecanismos: físicos, elétricos e químicos. Entre os últimos está a ação de neurohormonios adrenérgicos e catecolinérgicos em receptores específicos localizados na superfície da membrana. $\mathrm{O}$ acoplamento dos neurohormonios norepinefrina e acetilcolina com seus receptores de membrana beta-adrenérgicos e muscarínicos, respectivamente, ativa uma proteína citoplasmática transdutora de sinal denominada de proteína $\mathrm{G}^{15}$. Esta proteína, de estrutura similar a guanosina, apresenta pelo menos dois tipos: $\mathrm{G}_{\mathrm{s} \text {, }}$ ativada pelo receptor adrenérgico e $\mathrm{G}_{i}$, ativada pelo receptor colinérgico. Cada tipo é composto por três subunidades: alfa, gama e beta. A ativação da proteína $\mathrm{G}$ em decorrência da estimulação do beta-1 receptor adrenérgico promove a ligação da subunidade alfa da proteína $\mathrm{G}_{\mathrm{s}}$ com a guanosina trifosfasto (GTP) e a dissocia das demais subunidades gama e beta. A partir da liberação da subunidade alfa acoplada com guanosina trifosfato será deflagrada uma seqüência em cascata que envolve a ativação da adenil ciclase, produção de AMP cíclico, ativação da proteína cinase A e, como resultado final, aumento de condutância das correntes iônicas responsáveis pelas modificações do inotropismo, automatismo e refratariedade das células cardíacas. $O$ potencial de ação ${ }^{16}$ divide-se em cinco fases, as quatro primeiras (fases 0 a 3 ) correspondem à fase sistólica, enquanto a última (fase 4) está relacionada à diástole. A fase zero determina a velocidade de condução e resulta primariamente de um súbito aumento na permeabilidade da membrana ao sódio. A abertura dos canais de sódio ocorre, basicamente, em resposta a estímulos elétricos sendo que a rápida entrada deste íon na célula é responsável pela inversão da polaridade intracelular de -90 para $+130 \mathrm{mV}$. Em seguida à fase zero, a despolarização celular promove uma progressiva inativação dos canais de sódio e a abertura dos canais de cálcio. A corrente de cálcio é de menor amplitude, mais lenta que a de sódio, e somente se ativa quando o potencial transmembrana atinge valores menos negativos (tipicamente a partir de $-40 \mathrm{mV}$ ). É esta corrente lenta de cálcio a principal responsável pela formação do platô (fase 2) do potencial de ação; sua presença pode ser evidenciada após a inativação das correntes rápidas de sódio. Concomitante com essas correntes de cálcio, admite-se que haja outras correntes de influxo de sódio, também de baixa intensidade e que se inativa muito lentamente. O aumento de cálcio livre no citoplasma parece ativar uma corrente transitória de efluxo de potássio denominada ito. Esta corrente determina o entalhe repolarizante precoce do potencial de ação (fase 1) e, devido à distribuição não uniforme de seus canais no coração, parece ser responsável pela dispersão regional da amplitude da fase 2 no miocárdio ventricular, tanto em situações fisiológicas como não fisiológicas. Além dos canais de cálcio e da corrente Ito, a despolarização da célula favorece também a abertura dos canais de potássio retificadores tardios que são os principais determinantes da repolarização da célula (fase 3 do potencial de ação). Seis outros tipos de canais de potássio já foram descritos. Os três mais importantes $\mathrm{são}^{17}: 1$ ) retificador anômalo ( $\mathrm{iK}_{1}$ ), assim chamado por se comportar de maneira diferente daqueles canais inicialmente observados em axônios. São abertos quando o potencial intracelular se torna próximo ou negativo ao potencial de reversão do potássio (ponto de equilíbrio do potássio) e se fecham para potenciais positivos ao ponto de reversão. Este canal é o principal determinante do potencial de repouso do coração; 2) canal sensível à acetilcolina $\left(\mathrm{iK}_{\text {ach }}\right)$. É o principal determinante das respostas colinérgicas (muscarínicas) observadas no coração. Sua condutância é regulada pela ligação da acetilcolina com o receptor muscarínico presente na membrana plasmática e posterior ativação de uma proteína $\mathrm{G}$; 3) canal sensível ao ATP ( $\left.\mathrm{iK}_{\mathrm{atp}}\right)$. Este canal que se encontra normalmente fechado, somente entra em ação na presença de baixos níveis de ATP. Supõe-se que sua abertura seja determinada pela diminuição da fosforilação oxidativa, o que o leva a funcionar em condições fisiológicas adversas, como na isquemia miocárdica.

Algumas regiões do coração, como as células dos nódulos sinusal e atrioventricular, entre outras, dependem, predominantemente, da corrente lenta de cálcio para sua ativação. As propriedades eletrofisiológicas destas células se caracterizam por: baixo potencial de repouso que se situa em torno de $-65 \mathrm{mV}$ (tornando os canais de sódio inativos e, portanto, indisponíveis para abertura), baixa amplitude do potencial de ação, velocidade máxima de despolarização (10 V/s) bem menor que a das células de Purkinje (500 a 1000 $\mathrm{V} / \mathrm{s}$ ) e pela refratariedade prolongada.

\section{As Bases iônicas da ativação elétrica do coração do atleta}

A modulação do sistema nervoso autônomo sobre a frequiência cardíaca se faz primordialmente através de sua influência sobre o nódulo sinusal ${ }^{13}$. Este grupo de células possui a capacidade de formação do estímulo elétrico e é por este motivo denominado de células marcapasso. O nódulo sinusal, por gerar um maior número de estímulos por minuto em relação a outras células marcapasso (como o nódulo atrioventricular), constitui o foco que normalmente comanda o ritmo cardíaco. A capacidade de batmotropismo das células marcapasso é conseqüência da presença de uma maior densidade de um tipo de canal iônico responsável por uma corrente de entrada voltagem dependente, formada pelos cátions potássio e sódio e que se ativa em voltagens negativas a partir de $-40 \mathrm{mV}^{18}$. Esta corrente denominada de corrente marcapasso (If) promove uma despolarização diastólica espontânea até que se atinja o potencial limiar dos canais de cálcio tipo T que completam a despolarização. Quanto maior for a condutância da corrente If maior será o número de estímulos por minuto e, conseqüentemente, maior a frequiência cardíaca.

O tônus adrenérgico através da estimulação dos ß-receptores cardíacos e o tônus parassimpático pela estimulação de receptores muscarínicos tipo II modifica várias correntes iônicas ${ }^{13}$. O acoplamento da norepinefrina com re- 
ceptores $\beta-1$ ativa a proteína $\mathrm{G}_{\mathrm{s}}$ e promove a ligação de sua subunidade alfa com guanosina trifosfato liberando esta subunidade para interagir com enzimas citoplasmáticas. Em consequiência, ocorre a estimulação da enzima adenilciclase que irá catalisar a formação adenosina 3',5'-monofosfato cíclico (AMPc) a partir da adenosina trifosfato. $O$ aumento da concentração intracelular de AMPc regula várias funções celulares promovendo a fosforilação seletiva de proteínas incluindo a proteína Cinase A que irá, por sua vez, fosforilar as proteínas dos canais iônicos, levando ao aumento de suas condutâncias. Este incremento de condutância ocorre preferencialmente em três tipos de correntes: a corrente de cálcio tipo L gerando um aumento do inotropismo, a corrente de potássio retificadora tardia, levando ao encurtamento da repolarização e do período refratário, e a corrente If com conseqüente aumento da frequiência cardíaca.

O tônus vagal, através de liberação de acetilcolina, age de forma oposta reduzindo a frequiência cardíaca. A interação da acetilcolina com receptores muscarínicos dissocia a subunidade alfa da proteína $\mathrm{G}_{\mathrm{i}}$, liberando as subunidades gama e beta com conseqüente inibição da adenilciclase, redução AMPc intracelular e diminuição da condutância na corrente If. Existem evidências ${ }^{19}$ que a proteína $\mathrm{G}_{i}$ ativada através dos receptores muscarínicos pode diretamente, agindo como um segundo mensageiro, interagir com canais de potássios, promovendo um aumento do efluxo deste íon com conseqüente redução da frequiência cardíaca. A bradicardia sinusal é uma característica comum no eletrocardiograma do atleta.

O nódulo atrioventricular (NAV) pode ser dividido em três tipos básicos de células ${ }^{20}$ : células proximais, denominadas AN, que fazem fronteira entre o miocárdio atrial e a porção central do nódulo; células centrais, designadas com células $\mathrm{N}$, que compõem o nódulo $\mathrm{AV}$ compacto e células distais, chamadas de $\mathrm{NH}$, entre o nódulo atrioventricular compacto e o feixe de His. As características eletrofisiológicas de excitabilidade, condutividade e automatismo diferem entre o nódulo atrioventricular e o nódulo sinusal e entre os três tipos de células nodais ${ }^{18,21-24}$. A acetilcolina, além de reduzir a velocidade de despolarização diastólica da corrente If, ativa diretamente uma corrente de saída composta pelo íon potássio denominada Ik. Esta corrente dispensa, para sua ativação, o segundo mensageiro AMPc e é responsável pela hiperpolarização da célula. Esta hiperpolarização aumenta o gradiente de voltagem entre o potencial diastólico máximo e o potencial limiar de abertura dos canais de cálcio tipo $T$. Este aumento de gradiente alentece a condução elétrica no nódulo atrioventricular em especial nas células $\mathrm{N}$, sendo responsável pelos bloqueios de $1^{\circ}$ e $2^{\circ}$ grau que podem ocorrer na presença de intenso tônus vagal. Os canais da corrente If apresentam menor probabilidade de abertura em voltagens mais negativas (maiores que $-70 \mathrm{mV}$ ), desta forma a condutância desta corrente diminui durante a hiperpolarização. Esta característica é mais pronunciada no nódulo atrioventricular em relação ao nódulo sinusal fazendo com que a velocidade de despolarização seja mais lenta no primeiro mediante o fenômeno de hiperpolarização. Este fato faz com que o nódulo atrioventricular seja um marcapasso apenas subsidiário ou secundário, tanto em repouso como durante o exercício. As células NH apresentam limiares de ativação da corrente If mais próximos do nódulo sinusal e podem, durante atividade vagal, competir com o último pelo comando do ritmo cardíaco.

Existem características diversas do potencial de ação entre as células epicárdica e endocárdicas. Estas diferenças regionais nas propriedades eletrofisiológicas das células cardíacas estão associadas à uma proeminente fase 1 do potencial de ação das células epicárdicas ${ }^{25}$. Esta fase que constitui uma repolarização precoce deriva de uma corrente transitória de saída de potássio (Ito) ativada por voltagem e pelo cálcio ${ }^{26-29}$. Além de ser mais proeminente, a fase 1 das células epicárdicas apresenta uma maior dependência de sua magnitude em relação à freqüência cardíaca do que as células endocárdicas.

A estimulação ß-adrenérgica diminui a variação da amplitude da fase 1 nas células epicárdicas em função da variação da freqüência cardíaca ${ }^{30}$. A estimulação parassimpática ainda que possua um discreto efeito direto nos ventrículos, pode promover através do fenômeno de antagonismo acentuado, uma reversão do efeito do tônus simpático com conseqüente diminuição da freqüência cardíaca e incremento da variação da amplitude da fase 1 do potencial de ação epicárdico em relação ao endocárdico. Este processo deve produzir um gradiente de voltagem na fase 2 do potencial de ação, entre as células epicárdicas e endocárdicas, que se manifesta no eletrocardiograma pela elevação do ponto $\mathrm{J}^{31}$.

\section{O modelo vetorial do eletrocardiograma do atleta}

Em nossa opinião, associação entre a fase 1 do potencial de ação com suas diferenças eletrofisiológicas regionais e a onda $\mathrm{T}$ de atletas pode ser demonstrada pela teoria vetorial da despolarização e repolarização ventricular (figs. 1 e 2). A corrente despolarizante tem início no endocárdio e se dirige para o epicárdio gerando o complexo QRS no eletrocardiograma. Após o término da despolarização ocor-

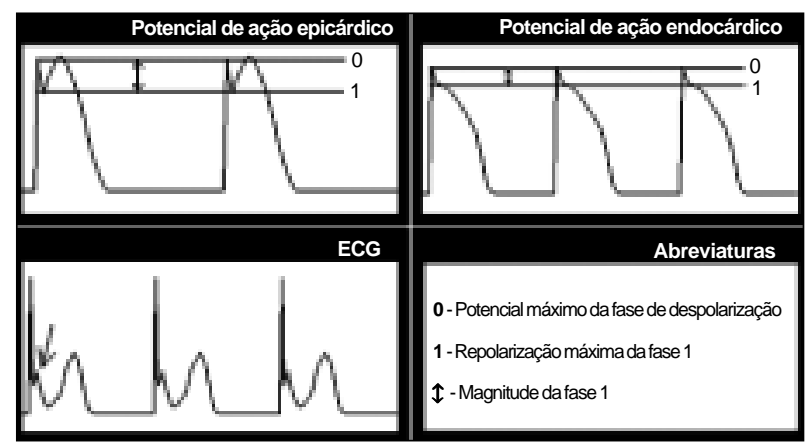

Fig. 1 - Diferenças eletrofisiológicas regionais do potencial de ação entre o epicárdio e endocárdio. Acima e à esquerda, potencial simulado de célula epicárdica com grande magnitude da fase 1 , conseqüente a uma proeminente repolarização precoce. Acima e à direita, potencial simulado de célula endocárdica com pequena amplitude da fase 1 . Em baixo à esquerda, eletrocardiograma decorrente das diferenças eletrofisiológicas regionais demonstrando o padrão de repolarização precoce. 


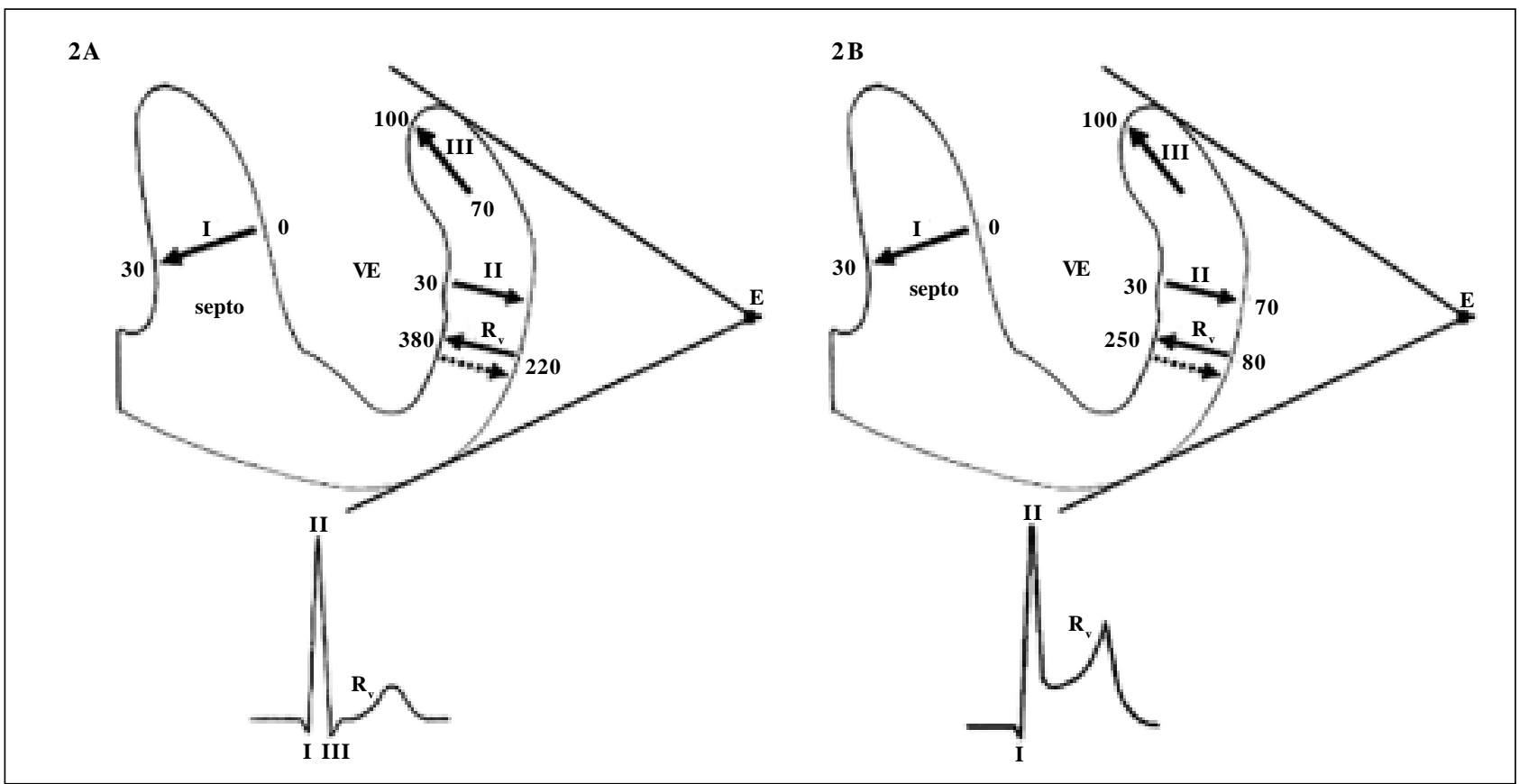

Fig. 2 - A) Representação da ativação elétrica transmural captada do eletrodo unipolar explorador (E). I, II e III representam os três vetores regionais (respectivamente septo, parede livre e parede póstero-basal) seqüenciais de despolarização ventricular. $\mathrm{R}$ representa o vetor da repolarização ventricular. Em cada um dos segmentos, os valores representam respectivos os tempos de ativação (em milisegundos) do início (cauda) e término (seta) da despolarização regional. A seta cheia, próxima a $R_{v}$, representa o sentido real (epicárdio-endocárdio), enquanto que a seta tracejada representa a direção do vetor repolarizante (endocárdio-epicárdio) como observada por E. Notar que entre o fim da despolarização (III) e o início da repolarização $\left(\mathrm{R}_{v}\right)$ existe um hiato de tempo de $120 \mathrm{~ms}$, que corresponde ao segmento $S T$ do eletrocardiograma; $\left.\mathrm{B}\right)$ o mesmo segmento representado em A. Observar que o início da repolarização $\left(R_{v}\right)$ precede em 20 ms o término da despolarização ventricular (III). Uma vez que $\mathrm{R}_{v}$ tem direção oposta ao vetor III, registra-se supradesnível do segmento $S T$ com concavidade superior, ocasionado pela interrupção da fase descendente da onda $R$ do eletrocardiograma, caracterizando a repolarização precoce.

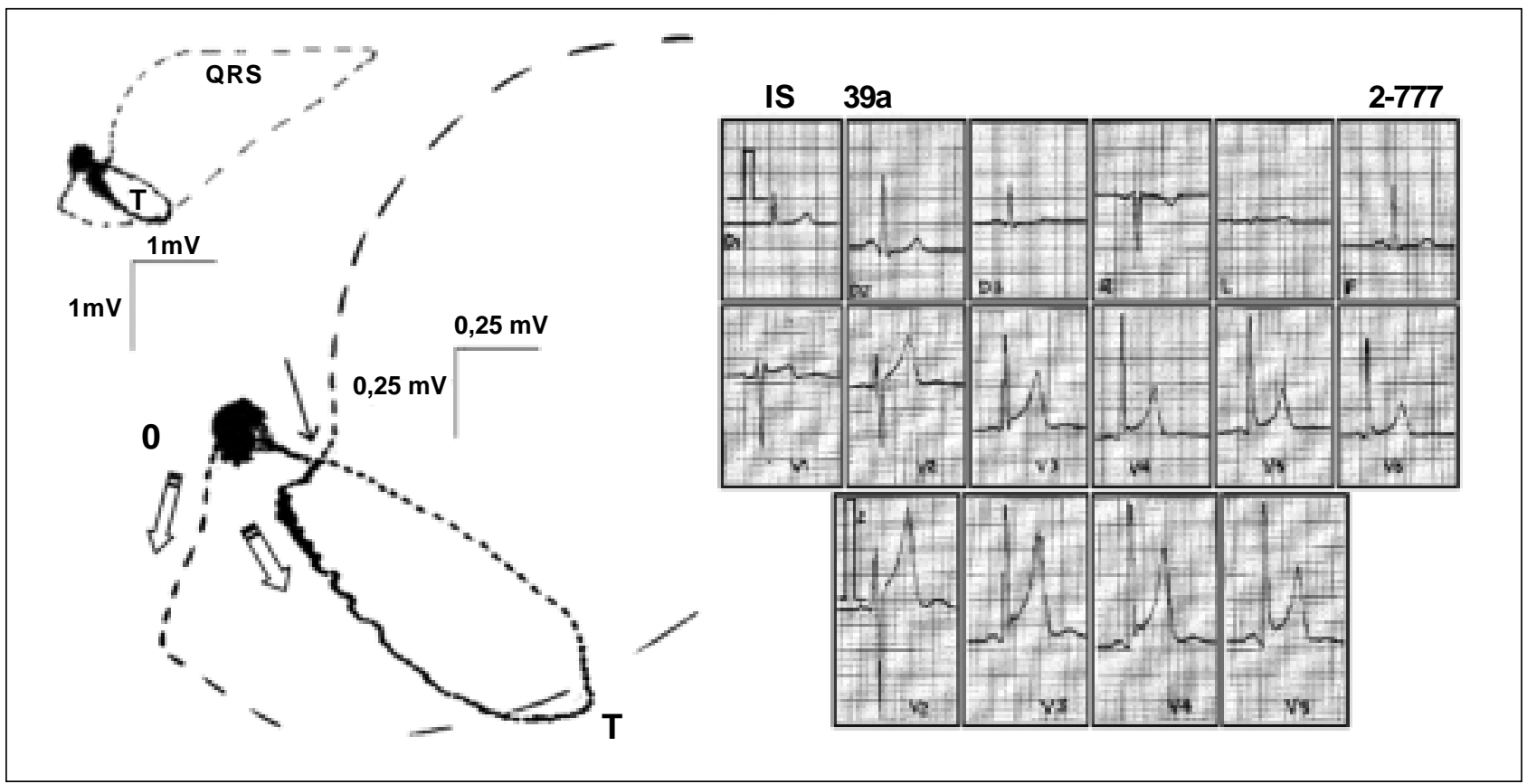

Fig. 3 -Eletrocardiograma e vetorcardiograma de indivíduo de 39 anos maratonista, com aspecto típico de vagotonia. Observar no eletrocardiograma o supradesnivelamento do segmento ST, representado no vetorcardiograma (em detalhe) pelo afastamento da porção terminal da alça QRS do ponto zero (seta cheia). Setas vazias indicam o sentido do giro anti-horário das alças QRSeT.Escalas de $1 \mathrm{mVe} 0,25 \mathrm{mV}$ do vetorcardiograma.

re um hiato de tempo que corresponde à fase 2 do potencial de ação e ao segmento ST no eletrocardiograma, antes do início da repolarização. Esta última, que é representada pela onda $\mathrm{T}$ no eletrocardiograma, se inicia mais precocemente no epicárdio e se dirige ao endocárdio. Como a repolarização é, ao contrário da despolarização, uma corrente de cargas negativas, ela se manifesta no eletrocardiograma como uma onda de similar polaridade à da despolarização ou seja, nas 
derivações, onde o complexo QRS é predominantemente positivo, a onda $T$ tende também a ser positiva. No caso de uma proeminente fase 1 nas células epicárdicas, esta corrente poderia ser detectada pelo eletrocardiograma de superfície, como uma repolarização precoce encurtando o segmento ST. Nas derivações onde predomina a onda R, como no caso das precordiais esquerdas, uma onda repolarizante precoce também positiva deve interromper a fase descendente da onda R, ocasionando o supradesnível do ponto $\mathrm{J}$ e segmento $\mathrm{ST}$. O aumento do número de células que repolarizam no sentido epicárdio-endocárdio, devido ao início ainda mais precoce da repolarização no epicárdio, poderia gerar ondas $\mathrm{T}$ de maior amplitude. Esta teoria é corroborada pelos achados vetocardiográficos de indivíduos vagotônicos. No plano horizontal, o retorno da alça do QRS ao ponto zero é interrompido por um início precoce da alça da onda T (fig. 3).

O aumento da atividade vagal e a bradicardia sinusal que ocorrem nos atletas poderiam, pelos mecanismos descritos, gerar através de suas modulações sobre a corrente Ito e a fase 1 do potencial de ação as alterações eletrocardiográficas de elevação de ponto J e segmento ST e ondas T com amplitude aumentada conhecidas como repolarização precoce ou cor vagotônico.

\section{Referências}

1. Scheuer J, Tipton CM. Cardiovascular adaptations to physical training. Ann Rev Physiol 1977; 39:221-7.

2. Bedford GB, Tipton CM. Exercise training and arterial baroreflex. J Appl Physiol 1987; 63:19-26.

3. Pagani M, Somers V, Furlan R, et al. Changes in autonomic regulation induced by physical training in mild hypertension. Hypertension 1988; 12:600-7.

4. Goldsmith RL, Bigger JT, Steinman RC et al. Comparison of 24-hour parasympathetic activity in endurance-trained and untrained young men. J Am Coll Cardiol $1992 ; 20: 552-8$

5. La Rovere MT, Mortara A, Sandrone G, et al. Autonomic nervous system adaptations to short-term exercise training. Chest 1992; 101(5 suppl):299s-303s.

6. DixonEM, Kamath MV, McCartney N, etal. Neural regulation of heart rate variability in endurance athletes and sedentary controls. Cardiovasc Res 1992;26:713-9.

7. Strano S, Lino S, Calcagnini G et al. Respiratory sinus arrhythmia and cardiovascular neural regulation in athletes. Med Sci Sports Exerc 1998; 30:215-219.

8. Sylvestre-Gervais L, Nadeau A, Nguyen MH, et al. Effects of physical training on $\beta$-adrenergic receptors in rat myocardial tissue. Cardiovasc Res 1982; 16:530-7.

9. Matsuo S, Nakamura Y, Takahashi M, et al. Cardiac Sympathetic Dysfunction in an Athlete's Herat Detected by 123 I-Metaiodobenzylguanidine Scintigraphy. Jpn Circ J 2001; 65: 371-4.

10. Estorch M, Serra-Grima R, Florats A, et al. Myocardial sympathetic innervation in the athlete's sinus bradycardia: is there selective inferior myocardial wall denervation? J Nucl Cardiol 2000; 7: 354-8.

11. Verani MS, Hartung GH, Hoepfel-Harris J, et al. Effects of exercise training on left ventricular performance and myocardial perfusion in patients with coronary artery disease. Am J Cardiol 1981; 47:797-891.

12. Billman GE, Schwartz PJ, Stone HL. The effects of daily exercise on susceptibility to sudden cardiac death. Circulation 1984; 69:1182-9.

13. Matthew NL: Time dependency of the autonomic interactions that regulate heart rate and rhythm. In: Zipes DP and Jalife J(Eds.): Cardiac Electrophysiology. From Cell to Bedside. Philadelphia, W.B. Saunders Company, 1995, p454-459.

14. Stein R, Medeiros CM, Guido AR, Zimerman LI, Ribeiro JP. Intrinsic sinus and atrioventricular node electrophysiologic adaptations in endurance athletes. J Am Coll Cardiol 2002; 39: 1033-8.

15. Stiles GL. Structure and Function of Cardiovascular Membranes Channels and Receoptors. In: Schlant RC and Alexander RE(Eds.): Hurst's The Heart: Arteries and Veins. New York, Mc Graw-Hill Inc., 1994 p 47-58.

16. Hanna MS, Dresdner Jr KP, Wit AL. Cellular Mechanisms of Cardiac Arrhythmias. In: El-Sherif N and Samet P (Eds): Cardiac Pacing and Electrophysiology. Philadelphia, W.B. Saunders Company, 1991 p 1-17.
17. Katz AM. Mechanisms of disease: cardiac ion channels. NEngl J Med 1993; 328 1244-51.

18. DiFrancescoD, Mangoni M, MaccaferriG. The pacemaker current in cardiac cells In: Zipes DP and Jalife J (Eds.): Cardiac Electrophysiology. From Cell to Bedside, Philadelphia, W.B. Saunders Company, 1995, p 96-103.

19. Codina J, Yatani A, Grenet D, et al. The subunit of the GTP binding proteina $G_{k}$ opens atrial potassium channels. Science 1987; 230:442-6.

20. Janse MJ, Van Capelle FJL, Anderson RH, et al. Electrophysiology and structure of the atrioventricular node of the isolated rabbit heart. In: Wellens HJJ, Lie KI, Janse MJ. The Conduction System of the Heart. Leiden, The Netherlands, Stenfert Kroese, 1976, p 296

21. Shier A, Adjemian RA, Munk AA. Ionic mechanisms of atrioventricular nodal cell excitability. In: Zipes DP and Jalife J(Eds.): Cardiac Electrophysiology. From Cell to Bedside. Philadelphia, W.B. Saunders Company, 1995, p 169.

22. Nishimura M, Habuchi Y, Hiromasa S, et al. Ionic Basis of depressed automaticity and conduction by acetylcholine in rabbit AV node. Am J Physiol 1988; 255(HCP24):H7.

23. Mazgalev T, Dreifus LS, Michelson EL, et al. Vagally induced hyperpolarization on atrioventricular node. Am J Physiol 1986; 251(HCP20):H631.

24. Tse WW. Suppressive effect of acetylcholine on action potentials of canine paranodal fibers. Am J Physiol 1986; 251(HCP20):H710.

25. Litovsky SH, Antzelevitch C. Transient outward current prominent in canine ventricular epicardium but not endocardium. Circ Res 1988; 62:116-26.

26. Giles W, Van Ginneken A. A transient outward current in isolated cells from the crista terminalis of rabbit heart. J Physiol 1988; 405:123-45.

27. Clark RB, Giles WR, Imaizumi Y. Properties of the transient outward current in rabbit atrial cells. J Physiol 1988; 405:147-68.

28. Apkon M, Nerbonne JM. Characterization of two distinct depolarization-activated K+ currents in isolated rat ventricular myocytes. J Gen Physiol 1991; 97 973-1011.

29. Nabauer M, Beuckelmann D, Erdmann E. Characteristics of transient outward current in human ventricular myocytes from patients with terminal heart failure. Circ Res 1993; 73:386-94.

30. Antzelevitch C, Sicouri S, Lukas A, et al. Regional differences in the Electrophysiology of ventricular cells: Physiological and clinical implications. In: Zipes DP and Jalife J (Eds.): Cardiac Electrophysiology. From Cell to Bedside, Philadelphia, W.B. Saunders Company, 1995 p 228-245.

31. Di Diego JM, Antzelevitch C. Cardiac innervation/conduction: high (Ca sup 2+) sub O-induced electrical heterogeneity and extrasystolic activity in isolated canine ventricular epicardium: phase 2 reentry. Circulation 1994; 89: 1839-50. 